\title{
Fast Biofilm Formation and Its Role on Power Generation in Palm Oil Mill Effluent Fed Microbial Fuel Cell
}

\author{
Maksudur R. Khan ${ }^{1, a}$, Baranitharan $E^{1}$., Prasad D. M. R. ${ }^{2}$ and Chin K. Cheng ${ }^{1}$ \\ ${ }^{1}$ Chemical and Natural resources engineering Department, University Malaysia Pahang, 26300 Gambang, Pahang, Malaysia \\ ${ }^{2}$ Petroleum and Chemical engineering Department, Institut Teknologi Brunei, BE1410 Gadong, Negara Brunei Darussalam, Brunei
}

\begin{abstract}
In the present study, fast formation and characterization of biofilm and its role on power generation in the microbial fuel cell (MFC) were investigated and the biofilm formation was also correlated with electrochemical behavior of the MFC. MFC was operated with palm oil mill effluent as substrate and carbon cloth as electrode. A biofilm comprising electrochemically active bacteria on the anode surface showed crucial effect to enhance the performance of the MFC. Infrared spectroscopy and thermogravimetric analysis confirmed the presence of biofilm and scanning electron microscopy examined a biofilm and microbial clumps on electrode surface. The current density was directly dependent on the biofilm growth and increased significantly during the initial growth. Electrochemical impedance spectroscopy was done to monitor the progress of the anode colonization by the microorganisms in the MFC. The findings of this study demonstrated that biofilm formation facilitated electron transport as well as decreased the charge transfer resistance of the anode and thus increased the power generation in the cell.
\end{abstract}

\section{Introduction}

Microbial fuel cell (MFC) is a bioelectrochemical energy system that opens a new window for eco friendly energy production to meet the growing demand and an economical pathway to a sustainable energy future. MFCs are capable of converting chemical energy available in organic substrates into electrical energy using bacteria as a biocatalyst to oxidize the biodegradable substrates [1]. The factors, such as substrate degradation, electrode material, type of microorganisms, rate of electron transfer from microorganisms to the anode, circuit resistance and proton mass transfer in the liquid mainly affect the MFC performance [2]. Different types of microorganisms have been studied in MFC such as Clostridium butyricum [3], Escherichia coli [4], Geobacter sulfurreducens [5], Klebsiella pneumoniae [6], Pseudomonas aeruginosa [7], Rhodoferax ferrireducens [8], Shewanella oneidensis [9], Shewanella putrefaciens [10] and so on. Eventhough, some pure cultures (e.g., Geobacter metallireducens, Shewanella putrefaciens and Pseudomonas aeruginosa) called electrogens are able to transfer electrons directly and produce current more or less equal to mixed cultures, it cannot utilize mixed or complex substrates. But, most of the industrial and domestic wastewater contains complex substrates and it makes pure culture not suitable for treating wastewater using MFC. Due to this reason, in most of the cases, anaerobic sludge [7] and activated sludge [11] obtained from wastewater treatment plant, have been used as inoclulum for the experiments. Therefore, these microorganisms should have grown and adapted to the condition of the wastewater.

Nevertheless, MFCs show real challenges to generate electric power for practical applications. Kim et al. [12] studied bacterial community structure (BCS), compartmentalization and activity in a MFC for a long period (18 months) and reported that BCS varied significantly in the anode biofilm. The research group as well showed that within 30 days of enrichment of microbial community was generated electricity $(0.2 \mathrm{~mA})$, using organic wastewater as the fuel [13]. Recently, Zhang, Zhu, Li, Liao and Ye [14] reported that biofilm is a crucial component in MFC for electrogenesis and it required only 14 days to be completely grown up at the anode compartment. Moreover, there are some barriers which limit the practical applications of MFCs, include ionic transfer restrictions, may increase the internal electrical resistance and oxygen transfer, therefore, decrease the overall cell performance [15]. Various attempts have been taken into account to overcome the electronic barrier. A number of electron-transfer mediators like biofilms have been used to facilitate electron transfer between an electrode and electrochemically active micro-organisms [16]. Anode potential is one of the most important factors at which the MFC is operated due to the control of theoretical energy gain for microorganisms [17]. In addition, the effect of external resistance applied to the electrical circuit also received wild attention and Zhang, $\mathrm{Zhu}, \mathrm{Li}$, Liao and $\mathrm{Ye}$ [14] reported that MFC performance increases with decreasing the applied external resistance [18] which may

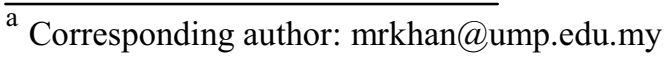


be due to the effect of the structure of the biofilm at the anode.

Further improvement in power generation from the MFC has been achieved by lowering the polarization resistance of the electrode (anode) which is highly dependent on the nature of the biofilm formed during the operation. Therefore, the study of biofilm formation has been considered as a crucial factor to ameliorate the performance of MFC. The study of rapidly formed biofilm based on palm oil mill anaerobic sludge and electrochemical impedance characteristics towards practical applications still suffers from lackings. In our previous study [19] we have used carbon felt as electrode but due to its large resistance it hindered the power generation. In order to avoid that, carbon cloth was used in this study because it has several advantages such as flexibility, highly porous and provides more surface area for bacterial growth.

In the present study, fast biofilm growth was correlated with electrochemical behavior of the MFC operated with palm oil mill effluent (POME) as substrate and carbon cloth as electrode. Electrochemical impedance spectroscopy (EIS) was employed to investigate the charge transfer resistance in the anode and SEM analysis was used to examine the biofilm.

\section{Materials and Methods}

\subsection{MFC construction}

The MFC was made of glass material (borosilicate) and was fabricated in china (Shangai sunny scientific, china). It consisted of two compartments; anode and cathode, with working volume of $450 \mathrm{~mL}$ each. The anode chamber of the MFC was filled with $450 \mathrm{~mL}$ of POME as substrate and $20 \mathrm{~mL}$ of anaerobic sludge (obtained from palm oil anaerobic sludge tank) as inoculum. At the same time, the cathode chamber was filled with $200 \mathrm{mg}^{-1} \mathrm{~L}^{-1}$ of $\mathrm{KMnO}_{4}$ solution. Carbon cloth (CC) was purchased from Shangai Sunny Scientific, China and used as electrode material for all the experiments. Equal size of CC (1.85 $\mathrm{cm}$ length and $5.5 \mathrm{~cm}$ height) was used in each compartment of dual chamber MFC experiment. The anode and cathode compartments were separated by a Nafion 117 membrane (Dupont Co., USA). Prior to use, $\mathrm{CC}$ was washed with water for several times to remove impurities. Nafion membrane was drenched overnight in dilute $\mathrm{HCl}$ and subsequently washed with deionized water before use. The anode and cathode electrodes were connected with a resistor by copper wires in order to make a circuit. The fuel cells were operated (batch mode) at ambient temperature of $25-28^{\circ} \mathrm{C}$.

\subsection{Measurement and analyses}

The voltage and current across an external $1 \mathrm{k} \Omega$ resistor was measured every $15 \mathrm{~min}$ by using digital multimeter with data logger (Fluke 289) which recorded and stored the data [20]. Later, it was retrieved from the multimeter using computer with fluke view forms software [21]. The polarization and power density curves were plotted using the voltage and current data. Power density normalized by volume $\left(\mathrm{P}_{\mathrm{v}}\right)$ and power density normalized by surface area $\left(\mathrm{P}_{\mathrm{A}}\right)$ were measured using the following equations:

$$
\begin{gathered}
P=V I \\
P_{A n}=\frac{V^{2}}{A_{A n} R} \\
P_{v}=\frac{V^{2}}{v R}
\end{gathered}
$$

Where $\mathrm{A}_{\mathrm{An}}=$ area of anode electrode $\left(\mathrm{m}^{2}\right), \mathrm{P}=$ power $(\mathrm{W}), \mathrm{V}=$ potential $(\mathrm{V}), \mathrm{v}=$ working volume of anode $\left(\mathrm{m}^{3}\right), \mathrm{R}=$ external resistance $(\Omega)$ and $\mathrm{I}=$ current flow $(\mathrm{A})$.

\subsection{COD removal efficiency}

COD was periodically checked by taking small amount of sample from the anode effluent for every $24 \mathrm{hrs}$. The COD removal efficiency $(\eta)$ was calculated as described by Baranitharan, Khan, Prasad and Salihon [19].

$$
\eta=(C O D)_{\text {initial }}-\operatorname{COD}_{\text {final }} / \operatorname{COD}_{\text {initial }} \times 100 \%
$$

Where $\mathrm{COD}_{\text {initial }}=$ initial $\mathrm{COD}$ concentration $\left(\mathrm{mg} \cdot \mathrm{L}^{-1}\right)$ and $\mathrm{COD}_{\text {final }}=$ final COD concentration $\left(\mathrm{mg}^{-1}\right)$.

\subsection{Coulombic efficiency}

The CE for complex substrates can be calculated for a fed batch system as described by Baranitharan, Khan, Prasad and Salihon [19].

$$
C E=\frac{8 \int_{0}^{t} I d t}{F V_{A n} \Delta C O D}
$$

Where $\Delta_{\mathrm{COD}}=$ Change in COD concentration $(\mathrm{mg} / \mathrm{L}), \mathrm{I}=$ current $(\mathrm{A}), \mathrm{t}=$ change in time $(\mathrm{s}), \mathrm{V}_{\mathrm{An}}=$ volume of liquid in anode compartment (1), F = Faraday's constant (96485 $\mathrm{C} / \mathrm{mol} \mathrm{e}^{-}$). In Eq. 5, 8 is a constant, based on $\mathrm{M}_{\mathrm{O} 2}=32$ for the molecular weight of oxygen and $b=4$ for the number of electrons exchanged per mole of oxygen.

\subsection{Sampling}

Raw POME and anaerobic sludge were collected from Felda palm oil industries located at Kuantan, Malaysia. The Raw POME was collected from the inlet of the mixing pond and the temperature of raw POME during collection was around 80 to $90^{\circ} \mathrm{C}$. Anaerobic sludge was obtained from bottom sampling port of anaerobic treatment plant. The samples were transported to the laboratory in sterile $1000 \mathrm{~mL}$ Schott bottles placed in ice and stored at $4^{\circ} \mathrm{C}$ until use.

\subsection{Wastewater and Inoculum characterization}


COD of POME was analyzed by standard methods [22]. The predominant microorganisms were characterized using BIOLOG GEN III (Biolog Inc., USA) test. In order to isolate microorganisms from anaerobic sludge, the samples were serially diluted and then pour plate technique was used to get individual colonies from the samples. Serial dilution was done until $10^{-6}$ dilution then pour plating was performed for the last three dilution of the sample alone $\left(10^{-6}, 10^{-5}\right.$ and $\left.10^{-4}\right)$ to get clear isolated colonies. The colonies were transferred to separate nutrient agar plates. Once the pure cultures from the samples were obtained, BIOLOG was carried out to identify the genus and species of microorganisms by performing carbon consumption tests with the isolated microorganisms.

\subsection{Infrared spectroscopy Thermogravimetric analysis (TGA)}

(IR)

and

Samples were prepared for IR test by drying at $120^{\circ} \mathrm{C}$ overnight to remove the water, and then $1 \mathrm{wt} \%$ sample was ground with dry $\mathrm{KBr}$. Samples were pressed into thin discs and analyzed on a Nicolet Avatar 370 DTGS FT-IR spectrophotomer under $\mathrm{N}_{2}$ atmosphere. TGA samples $(5 \mathrm{mg})$ were analyzed on TA Instruments Q500, thermogravimetric analyzer, at a heating rate of $10^{\circ} \mathrm{C}$ $\min ^{-1}$ in $\mathrm{N}_{2}$ ambient.

\subsection{Biofilm examination by SEM}

The samples for SEM analysis were prepared by a method described by Chae, Choi, Lee, Kim and Kim [23]. Parts of the CC were cut and removed from the anode chamber then rinsed with a sterile medium, and immediately fixed with an anaerobic solution of $2 \%$ glutaraldehyde and $1 \%$ formaldehyde. After immersion in $1 \%$ osmium tetroxide for $24 \mathrm{~h}$, samples were carefully rinsed three times in a HEPES buffer $(\mathrm{pH}$ 6.8) and once in deionized water. Samples were then subjected to a serial dehydration protocol using increased concentrations of ethanol $(10,25,50,75,90,100,100$, and 100) for $30 \mathrm{~min}$ for each stage with gentle periodic agitation and then dried completely at room temperature. Desiccated samples were coated with platinum and observed using a JEOL JSM7800F field emission SEM at $3 \mathrm{kV}$.

\subsection{Electrochemical impedance spectroscopy}

Electrochemical impedance spectroscopy (EIS) test was carried out using an electrochemical workstation (AUTOLAB 2273, PAR, USA). The three-electrode mode was employed to analyze the anode electrode. The anode and cathode electrodes were used as working electrode and counter electrode, respectively. The saturated $\mathrm{Ag} / \mathrm{AgCl}$ electrode was used as the reference electrode and was placed as close as possible to anode electrode [24]. Impedance measurements were conducted at the OCV (Open circuit voltage) of MFCs over a frequency range of $100 \mathrm{kHz}$ to $5 \mathrm{mHz}$. The Nyquist plots of the impedance spectra were analyzed using NOVA 1.9 (NOVA Software).

\section{Results and Discussion}

\subsection{Performance of MFC with POME}

The MFCs were fed with diluted POME with an initial COD concentration of $964 \mathrm{mg}$. $\mathrm{L}^{-1}$ and anaerobic sludge as inoculum for all the experiments as well. The predominant microorganisms present in the anaerobic sludge were identified as Pseudomonas aeruginosa, Pseudomonas mendocina, Pseudomonas viridiivida, Acetinobacter schindleri, Actinobacillus capsulatus and Brevibacterium paucivorans using the BIOLOG GEN III test. The current generation and COD removals of the palm mill wastewater in the MFC system over time are shown in Figure 1a. After 14 days of operation, the anode effluents showed a maximum COD removal of $63 \%$ and coulombic efficiency of about $26 \%$. From Fig. 1a, it was found that the current density tend to increase from day 1 until day 9 and a sharp increase in current generation was evident for 7 days of operation and COD removal efficiency was also increased at the same duration. The current density produced in MFC was directly dependent on the biofilm growth and increased significantly during the initial growth. From day 9 to day 14, the current density was found slightly decreased due to the accumulation of metabolite product such as the successive gathering of $\mathrm{H}^{+}$ions depressed the microbial activities [25]. The results showed that current densities and COD removals were proportionally increased with COD removal in MFC up to days 9 but after that period though the COD removal increased, current generation was not increased rather slightly dropped. This COD removal was presumably enriched due to biomass generation, incomplete biodegradation of the substrate, hydrogen production, methanogenesis and aerobic degradation [19]. Figure 1b demonstrates the polarization curves for the MFC operated for 14 days in order to yield anode biofilm with variable physical properties during the period. It is evident from the figure that after 3 days of operation there was little activity on the anode resulting in a low polarization performance. The biofilm development was fast between days 3 and 7 point out a significant enhancement in the cell performance. This improvement may be caused by the effect of microorganisms on the electrode surface amid efficient biofilm formation [20]. The maximum performance was observed on the 7th day of biofilm growth on the anode as shown in Figure 1b. After 7 days, there was a noticeable drop in the polarization performance which might be due to the accumulation of metabolic product such as the accumulation of $\mathrm{H}^{+}$ion depressed the microbial activities [26]. The power density profile follows the similar trend as that of the polarization performance with the excellent performance being showed by the MFC on 7th day. A maximum power density of $28 \mathrm{~mW} . \mathrm{m}^{-2}$ was found on 7 th day of operation which is comparatively higher than our previous study using carbon felt $\left(22 \mathrm{~mW} . \mathrm{m}^{-2}\right)$ as electrode [19]. Jahim et 
al. [26] also reported the similar trend studied by using palm oil mill effluent in MFC.

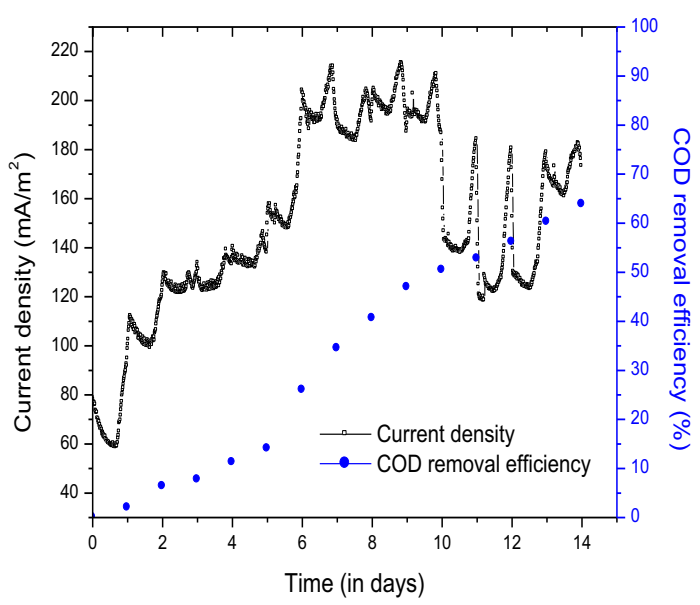

Figure 1a. Profile of current density and COD removal efficiency of carbon cloth MFC with time

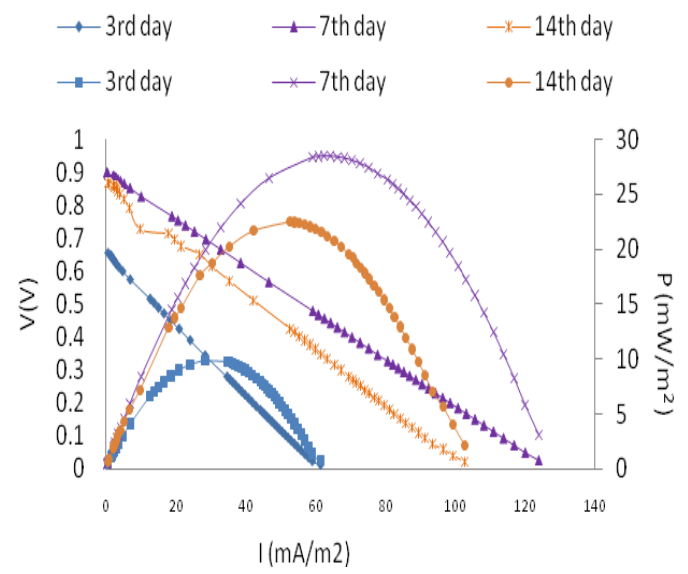

Figure 1b. Polarization and power density curves of carbon cloth MFC

\subsection{Biofilm characterization}

\subsubsection{Field emission scanning electron microscopy analysis (FESEM) of the biofilm}

Figure 2 represents the SEM of the anode surface, conducted before (Figure 2a) and after the operation (Figure $2 b$ and $2 c$ ) in the MFC in order to confirm the presence of biofilm on the electrode surface. In Figure $2 b$ and 2c, the SEM images showed at different magnification of biofilm growth on CC. Electron micrographs revealed unique biofilm structures and cell shapes. In the case of the higher magnification of SEM images (Figure 2c), the biofilm was formed by an interconnected fibre like structure which covers the electrode surface. Marsili, Rollefson, Baron, Hozalski and Bond [27] reported that the biofilm on an electrode surface contributed the key current through direct electron transfer. Figure $2 \mathrm{c}$ shows that biofilms were sparingly distributed on the CC along with highly complicated structures comprised of morphologically different cells. The important component of biofilms known as extracellular polymeric substances (EPS), are high-molecular weight compounds secreted by microorganisms and have a significant influence on the physico-chemical properties including electron transfer. Bacteria of various sizes and shapes were scattered around the electrode, associated with a biofilm formed on its surface. Besides that many rod-shaped cells can also be seen on the biofilm (Figure 2c) including loosely associated microbial clumps present on the electrode surface (CC). Kim et al. [12] have proposed that these microbial clumps consist of bacteria that ferment the complex fuel into simple fermentation products. These products can then be used as substrate for electrochemically active bacteria within the biofilm to generate electricity $[13,28]$.

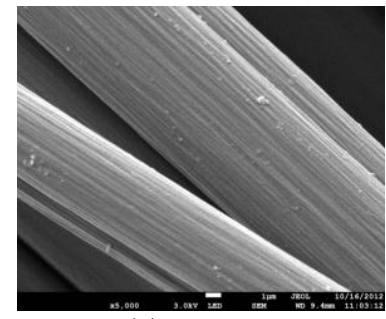

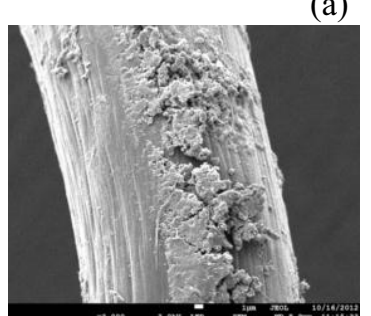

(b)

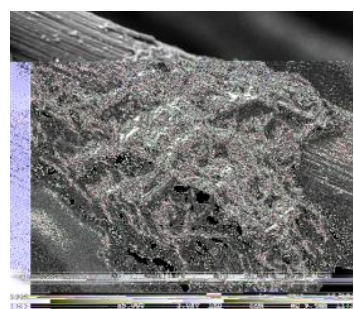

(c)
Figure 2. SEM images of (a) new carbon cloth (b and c) bacteria growing on anode carbon cloth in the MFC fed with POME as electron source for 14 days

\subsubsection{TGA analysis on biofilm}

Anodes were also examined by TGA before and after MFC operation at different intervals $\left(3^{\text {rd }}, 7^{\text {th }}\right.$ and $14^{\text {th }}$ day) as shown in Figure 3. Distinct changes in overall weight losses were observed in the conditions the operation carried out. The adhesion of a bacterial biofilm to an MFC anode affects the weight of the anode. Water adhered to the anode surfaces were probably contributed to the weight losses from 25 to $100^{\circ} \mathrm{C}$ due to evaporation [29]. Therefore, temperatures $>100^{\circ} \mathrm{C}$ up to $900^{\circ} \mathrm{C}$ was considered remarkable for gravimetric analysis of the anode. A $5 \%$ of the total weight loss from 100 to $700^{\circ} \mathrm{C}$ was observed before anode operation. A slight increase to $9 \%$ in anode was observed for the $3^{\text {rd }}$ day while further weight losses were observed to be $11 \%$ and $18 \%$ corresponding to the $7^{\text {th }}$ and $14^{\text {th }}$ days of the MFC treatment. A $3 \%$ change in weight loss was observed between $100^{\circ} \mathrm{C}$ and $200^{\circ} \mathrm{C}$ after 14 days of operation but there is almost no loss in anode before operation. This is a temperature range where bacterial organic matter is likely to decompose and burn, and thus this difference is attributed to a bacterial biofilm [29]. It is known that 
bacterial biofilms commonly form fibrilar and mushroom like structures [30]. The types of structures composing the biofilm and their densities are likely to affect the temperature that weight losses occur [29]. Two distinct weight loss events were observed during anode heating for $3^{\text {rd }}, 7^{\text {th }}$ and $14^{\text {th }}$ days of operation. On $3^{\text {rd }}$ day, $2.04 \%$ from 100 to $290^{\circ} \mathrm{C}, 3.84 \%$ from 300 to $650^{\circ} \mathrm{C}$ were observed whereas on $7^{\text {th }}$ day, $2.8 \%$ from 100 to $290^{\circ} \mathrm{C}$ and $2.6 \%$ from 300 to $650^{\circ} \mathrm{C}$ were observed and on $14^{\text {th }}$ day, $5 \%$ loss from 100 to $290^{\circ} \mathrm{C}$ and $10 \%$ loss from 300 to $550^{\circ} \mathrm{C}$ were observed. Moreover, at higher temperatures the weight loss showed sharp downward trends may be due to the decomposition of biofilms at the anode surface. The changes in TGA profiles may be attributed to the increased amount of biofilm formation and sustain the effective biofilm as electron carrier on the electrode surface.

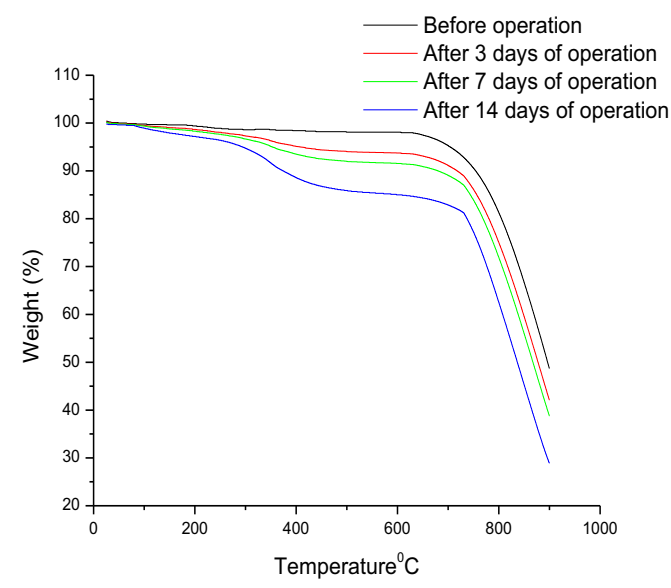

Figure 3. TGA spectrums of $\mathrm{CC}$ anodes before and after MFC treatment

\subsubsection{FTIR analysis of the biofilm}

The anode examined by FT-IR before and after MFC operation at different intervals $\left(3^{\text {rd }}, 7^{\text {th }}\right.$ and $14^{\text {th }}$ days $)$ is shown in Figure 4. The broad band observed in the 3500$3300 \mathrm{~cm}^{-1}$ range attributed to the free and bound $\mathrm{O}-\mathrm{H}$ and $\mathrm{N}-\mathrm{H}$ groups, which could form hydrogen bonding with the carbonyl group of the peptide linkage in the protein. The main bands of peptide linkage were related to $\mathrm{C}=\mathrm{O}$ stretching at $1643 \mathrm{~cm}^{-1}$ (amide $\mathrm{I}$ ) and $\mathrm{N}-\mathrm{H}$ banding at $1505 \mathrm{~cm}^{-1}$ (amide II) [31]. The bands at $2917 \mathrm{~cm}^{-1}$ and $2852 \mathrm{~cm}^{-1}$ can be attributed to the functional groups of membrane fatty acids and also by some amino acid sidechain vibrations since here the characteristic $\mathrm{C}-\mathrm{H}$ stretching vibrations of $-\mathrm{CH}_{3}$ and $=\mathrm{CH}_{2}$ functional groups dominate [32]. The FT-IR spectrum of the anode after MFC operation also revealed that the band observed in the 1200 and $900 \mathrm{~cm}^{-1}$ range is due to the symmetric stretching vibration of $\mathrm{PO}_{2}^{-}$groups found in nucleic acids and to $\mathrm{C}-\mathrm{O}-\mathrm{C}$ and $\mathrm{C}-\mathrm{O}-\mathrm{P}$ stretching, which exposes the occurrence of carbohydrates and polysaccharides in the cell wall but also the influence of nucleic acids [33]. These results confirm the presence of biofilm on the surface of the electrode.

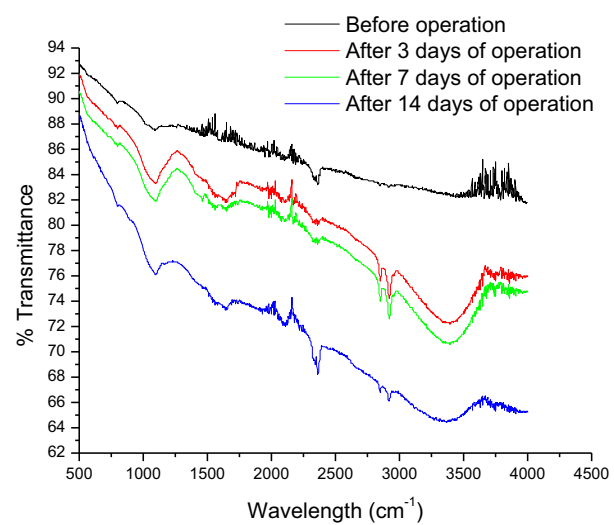

Figure 4. IR spectra of CC anodes before and after MFC treatment

\subsection{Electrochemical impedance spectroscopy}

Figure 5 shows the Nyquist plots for the anode configuration on $3^{\text {rd }}, 7^{\text {th }}$ and $14^{\text {th }}$ days of operation. The real axis $(Z)$ intercept of the Nyquist curves in the high frequency region correspond to the time-independent ohmic resistance in the anode configuration. The magnitude of the Nyquist arc qualitatively yields the electrochemical polarization resistance of the working electrode in anode configuration, while the quantitative values can be obtained by equivalent circuit (EC) fitting of the data [34]. After the reactor startup, the electrochemical impedance spectroscopy of the anode was tested. The impedance spectra of the anode MFC were analyzed by fitting to the equivalent circuit (EC): $\mathrm{R}(\mathrm{C}[\mathrm{RW}])$ as shown in Figure 5 where $\mathrm{R}_{1}, \mathrm{R}_{2}\left(\mathrm{R}_{\mathrm{ct}}\right), \mathrm{C}$ and $\mathrm{W}$ represent the ohmic resistance, charge transfer resistance, capacitance and mass transfer resistance respectively [35]. In Fig. 5, it can be seen that the EIS data were fitted well with the equivalent circuit model and an electric circuit is shown in the upper part of the figure. The $\mathrm{R}_{\mathrm{ct}}$ values on $7^{\text {th }}$ and $14^{\text {th }}$ days were found to be $22.07 \Omega$ and $20.09 \Omega$ respectively. In Nyquist plot, on $3^{\text {rd }}$ day although the ohmic resistance was low, the charge transfer resistance semicircle was not formed which might be due to the absence of biofilm on electrode surface while on $7^{\text {th }}$ and $14^{\text {th }}$ days semicircle was evident due to the presence of biofilm which causes charge transfer resistance. It is interesting to note that the anode charge transfer resistance $\left(\mathrm{R}_{\mathrm{ct}}\right)$ after 14 days of continuous microbial growth was more or less same as that on day 7. Our previous results [20] showed that stable biofilm can be formed within even 7 days of MFC operation and these results support the same. A biofilm formed on the electrode surface during the MFC operation with anaerobic sludge, was usually enriched with electrochemically active bacteria [13] which might reduce the charge transfer resistance. As a result, the development of the microbial biofilm on the anode was found to be decreased the polarization resistance and facilitates the kinetics of the electrochemical reactions [20]. This investigation confirmed the fact that the anode charge transfer resistance is strongly influenced by the microbes growing on the anode surface. 


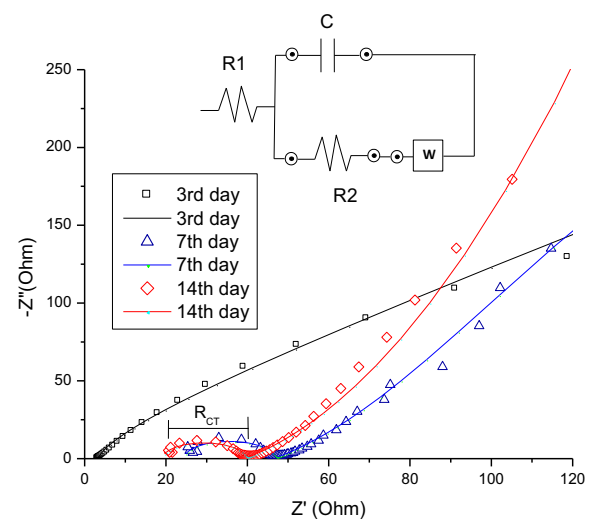

Figure 5. EIS data of MFC with CC after 14 days of operation

\section{Conclusion}

It can be concluded that the current density produced in MFC was directly dependent on the biofilm growth and increased significantly during the initial growth. FTIR and TGA results confirmed the presence of biofilm formation on anode while FESEM showed the highly complicated structures comprised of morphologically different cells in the biofilm. The maximum power generation and coulombic efficieny achieved in MFC using carbon cloth $\left(28 \mathrm{~mW} / \mathrm{m}^{2}, 26 \%\right)$ were comparitvely higher than carbon felt $\left(22 \mathrm{~mW} / \mathrm{m}^{2}, 24 \%\right)$. The EIS results confirmed that anodic $R_{c t}$ values from $7^{\text {th }}(22.07 \Omega)$ to $14^{\text {th }}(20.09 \Omega)$ days were more or less the same, which proves the presence of stable fast biofilm formation on and after 7 days of MFC operation.

\section{References}

1. R. Karthikeyan, A. Selvam, K.Y. Cheng, and J.W.-C. Wong, Bioresour. Technol. 200, 845-852 (2016).

2. S. Velasquez-Orta, I. Head, T. Curtis, and K. Scott, Bioresour. Technol. 102, 5105-5112 (2011).

3. R.C. Wagner, S. Porter-Gill, and B.E. Logan, AMB express. 2, 1-6 (2012).

4. T.H. Han, M.H. Cho, and J. Lee, Biotechnol. Bioprocess Eng. 19, 126-131 (2014).

5. K. Inoue, C. Leang, A.E. Franks, T.L. Woodard, K.P. Nevin, and D.R. Lovley, Environ Microbiol Rep. 3, 211-217 (2011).

6. L.-Z. Zeng, S.-F. Zhao, and W.-S. Li, Appl Biochem Biotech. 175, 2637-2646 (2015).

7. M.H.M. Nor, M.F.M. Mubarak, H.S.A. Elmi, N. Ibrahim, M.F.A. Wahab, and Z. Ibrahim, Bioresour. Technol. 190, 458-465 (2015).

8. S.K. Chaudhuri, and D.R. Lovley, Nature Biotechnol. 21, 1229-1232 (2003).

9. L.A. Fitzgerald, E.R. Petersen, B.J. Gross, C.M. Soto, B.R. Ringeisen, M.Y. El-Naggar, and J.C. Biffinger, Biosens. Bioelectron. 31, $492-498$ (2012).

10. S. Pandit, S. Khilari, S. Roy, D. Pradhan, and D. Das, Bioresour. Technol. 166, 451-457 (2014).

11. X. Mei, C. Guo, B. Liu, Y. Tang, and D. Xing, RSC Adv. 5, 78136-78141 (2015).
12. G. Kim, G. Webster, J. Wimpenny, B. Kim, H. Kim, and A. Weightman, J. Appl Microbiol. 101, 698-710 (2006).

13. B. Kim, H. Park, H. Kim, G. Kim, I. Chang, J. Lee, and N. Phung, Appl Microbiol Biotechnol. 63, 672681 (2004).

14. L. Zhang, X. Zhu, J. Li, Q. Liao, and D. Ye, J. Power Sources. 196, 6029-6035 (2011).

15. A. Gugliuzza, and A. Basile, Membranes for clean and renewable power applications, (Woodhead Publishing, 2014).

16. A.E. Franks, N. Malvankar, and K.P. Nevin, Biofuels. 1, 589-604 (2010)

17. R.C. Wagner, D.F. Call, and B.E. Logan, Environ. Sci. Technology. 44, 6036-6041 (2010).

18. A.G. del Campo, P. Cañizares, J. Lobato, M. Rodrigo, and F.F. Morales, (2014).

19. E. Baranitharan, M.R. Khan, D. Prasad, and J.B. Salihon, Water Air Soil Pollut. 224, 1-11 (2013).

20. E. Baranitharan, M.R. Khan, D. Prasad, W.F.A. Teo, G.Y.A. Tan, and R. Jose, Bioprocess and Biosyst Eng. 1-10 (2014).

21. E. Baranitharan, M.R. Khan, A. Yousuf, W.F.A. Teo, G.Y.A. Tan, and C.K. Cheng, Fuel. 143, 72-79 (2015).

22. E.W. Rice, L. Bridgewater, and A.P.H. Association, Standard methods for the examination of water and wastewater, (American Public Health Association Washington, DC, 2012).

23. K.-J. Chae, M.-J. Choi, J.-W. Lee, K.-Y. Kim, and I.S. Kim, Bioresour. Technol. 100, 3518-3525 (2009).

24. Z. He, and F. Mansfeld, Energy Environ Sci. 2, 215219 (2009).

25. L. SweeSu, J.M. Jahim, W. Wan Ramli, M. Ismail, N. Anuar, S.K. Kamarudin, and S.N. Shari, J Appl Sci. 10, 3355-3360 (2010)

26. J. Jahim, W. Wan Ramli, M. Ismail, N. Anuar, S.K. Kamarudin, and S.N. Shari, J Appl Sci. 10, $3355-$ 3360 (2010).

27. E. Marsili, J.B. Rollefson, D.B. Baron, R.M. Hozalski, and D.R. Bond, Appl. Environ. Microbiol. 74, 7329-7337 (2008).

28. J. Lee, N.T. Phung, I.S. Chang, B.H. Kim, and H.C. Sung, FEMS Microbiol Lett. 223, 185-191 (2003).

29. J. Kramer, S. Soukiazian, S. Mahoney, and J. HicksGarner, J. Power Sources. 210, 122-128 (2012).

30. B.E. Rittmann, Microbial biofilms. ASM Press, Washington, DC. 359-378 (2004).

31. S. Karnnet, P. Potiyaraj, and V. Pimpan, Polym Degrad Stabil. 90, 106-110 (2005).

32. P.K. Nanda, K. Krishna Rao, and P.L. Nayak, J. Appl. Polym. Sci. 103, 3134-3142 (2007a).

33. D. Naumann, Encyclopedia of analytical chemistry. (2000).

34. E. Barsoukov, and J.R. Macdonald, Impedance spectroscopy: theory, experiment, and applications, (John Wiley \& Sons, New York, 2005).

35. Z. He, N. Wagner, S.D. Minteer, and L.T. Angenent, Environ. Sci. Technol. 40, 5212-5217 (2006). 